\title{
Neuronal SH2B1 is essential for controlling energy and glucose homeostasis
}

\author{
Decheng Ren, Yingjiang Zhou, David Morris, Minghua Li, Zhiqin Li, and Liangyou Rui \\ Department of Molecular and Integrative Physiology, University of Michigan Medical School, Ann Arbor, Michigan, USA.
}

\begin{abstract}
SH2B1 (previously named SH2-B), a cytoplasmic adaptor protein, binds via its Src homology 2 (SH2) domain to a variety of protein tyrosine kinases, including JAK2 and the insulin receptor. SH2B1-deficient mice are obese and diabetic. Here we demonstrated that multiple isoforms of SH2B1 ( $\alpha, \beta, \gamma$, and/or $\delta)$ were expressed in numerous tissues, including the brain, hypothalamus, liver, muscle, adipose tissue, heart, and pancreas. Rat SH2B1 $\beta$ was specifically expressed in neural tissue in $S H 2 B 1$-transgenic $\left(S H 2 B 1^{T g}\right)$ mice. $S H 2 B 1^{T g}$ mice were crossed with $S H 2 B 1$-knockout $\left(S H 2 B 1^{K O}\right)$ mice to generate $S H 2 B 1^{T g K O}$ mice expressing $S H 2 B 1$ only in neural tissue but not in other tissues. Systemic deletion of the $\mathrm{SH} 2 \mathrm{~B} 1$ gene resulted in metabolic disorders in $\mathrm{SH} 2 \mathrm{~B} 1^{\mathrm{KO}}$ mice, including hyperlipidemia, leptin resistance, hyperphagia, obesity, hyperglycemia, insulin resistance, and glucose intolerance. Neuron-specific restoration of SH2B1 $\beta$ not only corrected the metabolic disorders in $S H 2 B 1^{T g K O}$ mice, but also improved JAK2-mediated leptin signaling and leptin regulation of orexigenic neuropeptide expression in the hypothalamus. Moreover, neuron-specific overexpression of SH2B1 dose-dependently protected against high-fat diet-induced leptin resistance and obesity. These observations suggest that neuronal SH2B1 regulates energy balance, body weight, peripheral insulin sensitivity, and glucose homeostasis at least in part by enhancing hypothalamic leptin sensitivity.
\end{abstract}

\section{Introduction}

Body weight is controlled by a balance between energy intake and expenditure. Excess energy derived from a positive energy imbalance is stored as triglyceride (TG) in adipose tissue, resulting in obesity. Body weight is maintained within a narrow range by a homeostatic control system in which the brain, particularly the hypothalamus, senses and integrates various neuronal, hormonal, and nutrientrelated signals, thereby coordinating food intake and energy expenditure. Recent findings provide a framework for understanding this homeostatic regulation of body weight. Leptin, which serves as an essential adiposity signal, is produced primarily by white adipose tissue to convey information about peripheral energy storage and availability to the hypothalamus (1-3). Genetic deficiency of either leptin or its receptor disrupts the communication between the peripheral energy stores and the central sensors/integrators, resulting in severe energy imbalance and morbid obesity (4-8). Leptin resistance plays a key role in the development of obesity, which is a primary risk factor for type 2 diabetes and various cardiovascular disorders.

Leptin binds to and activates its long form receptor (LEPRb) in the hypothalamus, initiating the activation of a variety of intracellular signaling pathways, including the STAT3 and PI3K pathways (8-12). Inhibition of either the STAT3 or PI3K pathways in the hypothalamus results in leptin resistance and obesity, demonstrating an essential role for these 2 pathways in mediating leptin regulation of energy metabolism and body weight (11-17). JAK2, a cytoplasmic tyrosine kinase, binds directly to LEPRb and is activated in response to leptin $(9,18)$. Activated JAK2 phosphory-

Nonstandard abbreviations used: AgRP, agouti-related protein; GH, growth hormone; GTT, glucose tolerance test; HFD, high-fat diet; IRS1, insulin receptor substrate 1; ITT, insulin tolerance test; LEPRb, long form of the leptin receptor; MEF, mouse embryonic fibroblast; NPY, neuropeptide Y; NSE, neuron-specific enolase; $\mathrm{PH}$, pleckstrin homology; POMC, proopiomelanocortin; SH2, Src homology 2; TG, triglyceride; $\operatorname{TgKO}$, transgenic/knockout compound mutation.

Conflict of interest: The authors have declared that no conflict of interest exists. Citation for this article: J. Clin. Invest. 117:397-406 (2007). doi:10.1172/JCI29417. lates and activates downstream signaling molecules, including STAT3, insulin receptor substrate 1 (IRS1) and IRS2 (19). JAK2 is targeted by multiple negative regulators. PTP1B, a protein tyrosine phosphatase, binds to and dephosphorylates JAK2, thereby inhibiting JAK2 activation (20). Genetic deletion of PTP1B improves leptin sensitivity and protects against high-fat diet-induced (HFDinduced) obesity $(21,22)$. SOCS3 also inhibits JAK2 activation $(23,24)$. Both systemic SOCS3 haploinsufficiency and hypothalamus-specific deletion of SOCS3 improve leptin sensitivity $(25,26)$. Recent studies suggest that JAK2 may also be positively regulated by $\mathrm{SH} 2-\mathrm{B}$, a JAK2-interacting protein (27).

$\mathrm{SH} 2-\mathrm{B}$ is one of 3 members of the SH2B family (SH2-B, APS, and Lnk), which have a conserved structure of a pleckstrin homology (PH) and Src homology 2 (SH2) domain (28-30). SH2-B, APS, and Lnk were recently renamed $\mathrm{SH} 2 \mathrm{~B} 1, \mathrm{SH} 2 \mathrm{~B} 2$, and $\mathrm{SH} 2 \mathrm{~B} 3$, respectively, by the HUGO Gene Nomenclature Committee. The SH2B1 $(S H 2-B)$ gene encodes, via alternative mRNA splicing, 4 isoforms $(\alpha, \beta, \gamma$, and $\delta)$ that share an identical $\mathrm{N}$-terminal region, including both $\mathrm{PH}$ and $\mathrm{SH} 2$ domains, but differ at their $\mathrm{C}$ termini following the SH2 domain (31). Since all forms contain conserved PH and $\mathrm{SH} 2$ domains, they are predicted to have similar functions. In cultured cells, SH2B1 binds via its $\mathrm{SH} 2$ domain to numerous protein tyrosine kinases, including both cytoplasmic tyrosine kinases (e.g., JAK1, JAK2, and JAK3) and receptor tyrosine kinases (e.g., the receptors for insulin, IGF-1, PDGF, FGF, nerve growth factor, brain-derived neurotrophic factor, and glial cell-derived neurotrophic factor) $(29,32-43)$. In animals, systemic deletion of $\mathrm{SH} 2 \mathrm{~B} 1$ results in morbid obesity and type 2 diabetes, demonstrating that $\mathrm{SH} 2 \mathrm{~B} 1$ is an essential player in the regulation of both body weight and glucose metabolism (44-46). In addition to obese and diabetic phenotypes, $S H 2 B 1$-knockout mice also have defects in reproduction (47).

SH2B1 is abundantly expressed in both the central nervous system and peripheral tissues, including the brain, liver, muscle, and adipose tissue. However, relative contributions of SH2B1 in 
$\mathbf{A}$

B
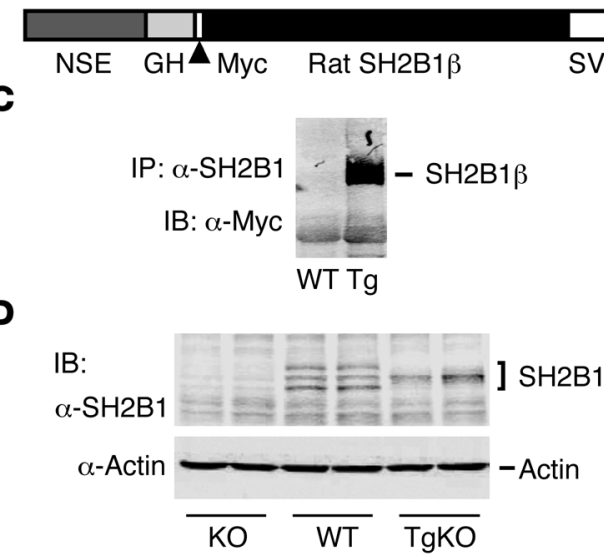

$\mathbf{E}$

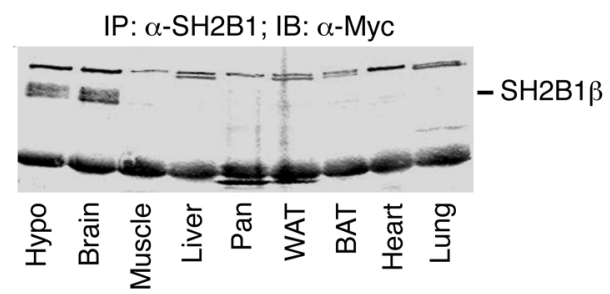

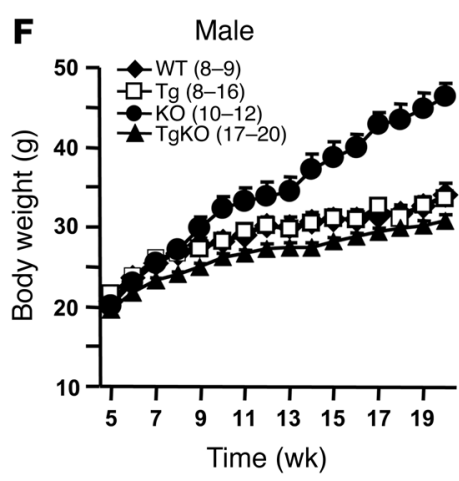

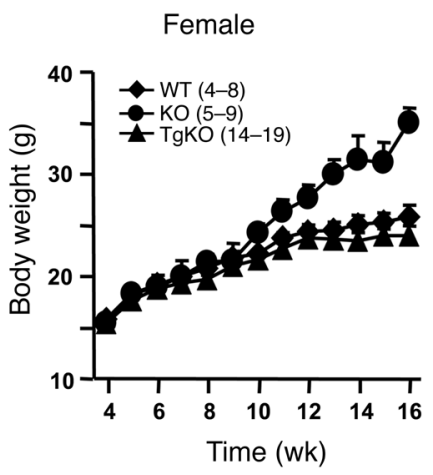

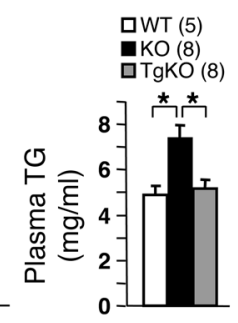
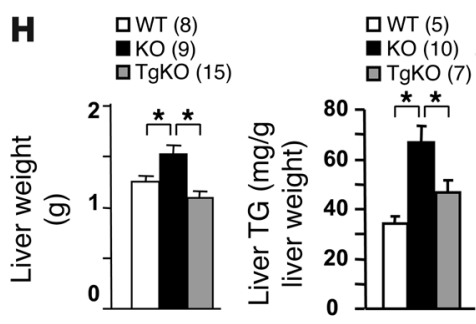

Figure 1

Neuron-specific restoration of SH2B1 $\beta$ rescues obesity and hyperlipidemia in SH2B1 ${ }^{\mathrm{KO}}$ mice. (A) Tissue extracts (2 mg protein in hypothalamic and $3 \mathrm{mg}$ protein in other tissue extracts) were prepared from WT mice, immunoprecipitated with $\alpha$-SH2B1, and immunoblotted with $\alpha$-SH2B1. Lanes 1-8 represent tissue extracts from spleen, pancreas, heart, hypothalamus, muscle, liver, white adipose tissue, and brain, respectively. (B) Schematic representation of the Myc-tagged SH2B1 $\beta$ transgene. (C) Brain extracts were prepared from an SH2B1 $1^{\mathrm{Tg}}$ mouse and a WT littermate, immunoprecipitated with $\alpha-\mathrm{SH} 2 \mathrm{~B} 1$, and immunoblotted with $\alpha$-Myc. (D) Brain extracts were prepared from WT, SH2B1KO, and SH2B1TgKO-437 mice and immunoblotted with $\alpha-\mathrm{SH} 2 \mathrm{~B} 1$. Each lane represents a sample from 1 mouse. (E) Tissue extracts were prepared from the hypothalamus (Hypo), brain, skeletal muscle, liver, pancreas (Pan), white adipose tissue (WAT), brown adipose tissue (BAT), heart, and lung from an SH2B1TgKO-437 female (16 weeks old); immunoprecipitated with $\alpha$-SH2B1; and immunoblotted with $\alpha$-Myc. (F) Growth curves for WT, SH2B1Tg, $S H 2 B 1^{K O}$, and $S H 2 B 1^{T g K O}-437$ mice. Number in parentheses indicates the number of mice per group. (G) Levels of plasma FFAs and TGs in males (17 weeks old) fasted overnight. (H) Liver weight and TG levels in mice (21-22 weeks old) fasted overnight. ${ }^{*} P<0.05$.

individual tissues to energy and/or glucose homeostasis remain unclear. This study investigated the potential role of central versus peripheral SH2B1 in regulating energy and glucose metabolism and provides convincing evidence that central rather than peripheral SH2B1 controls body weight, peripheral insulin sensitivity, and glucose metabolism at least partially by cell-autonomously enhancing leptin sensitivity in the hypothalamus.

\section{Results}

Neuron-specific restoration of $S H 2 B 1$ rescues obesity and byperlipidemia in SH2B1 ${ }^{\mathrm{KO}}$ mice. To determine tissue distribution of SH2B1, tissue extracts were prepared from spleen, pancreas, heart, hypothalamus, skeletal muscle, liver, white adipose tissue, and brain of WT mice. Tissue extracts were immunoprecipitated with antiSH2B1 antibody ( $\alpha$-SH2B1) and immunoblotted. $\alpha$-SH2B1, which was raised against a fusion protein of glutathione- $S$ transferase full-length rat $\mathrm{SH} 2 \mathrm{~B} 1 \beta$, specifically recognizes all isoforms of $\mathrm{SH} 2 \mathrm{~B} 1(\alpha, \beta, \gamma$, and $\delta)$; in contrast, previously reported anti-SH2B1 antibodies preferentially recognize SH2B1 $\beta$ (44). Multiple forms of SH2B1 were detected in spleen, pancreas, hypothalamus, and brain (Figure 1A, lanes 1, 2, 4, and 8). In con- trast, the heart, muscle, liver and adipose tissues predominantly expressed the fastest-migrating form of SH2B1 (Figure 1A, lanes 3 and 5-7).

To determine the role of SH2B1 in the brain, recombinant $\mathrm{SH} 2 \mathrm{~B} 1 \beta$ was specifically expressed in neural tissue under the control of the neuron-specific enolase (NSE) promoter/rat growth hormone $(\mathrm{GH})$ enhancer. A similar NSE promoter/GH enhancer has been successfully used to drive the expression of LEPRb and proopiomelanocortin (POMC) transgenes in the hypothalamus, respectively, resulting in a reduction in both adiposity and body weight $(48,49)$. Rat SH2B1 $\beta$ cDNA was inserted into a transgenic vector 3 '-end of the NSE promoter/GH enhancer sequences (Figure 1B). A Myc tag was engineered at the $\mathrm{N}$ terminus of $\mathrm{SH} 2 \mathrm{~B} 1 \beta$ to facilitate the detection of recombinant $\mathrm{SH} 2 \mathrm{~B} 1 \beta$ expression. The $\mathrm{SH} 2 \mathrm{~B} 1 \beta$ transgenic construct was used to generate heterozygous SH2B1-transgenic $\left(\mathrm{SH} 2 \mathrm{~B} 1^{\mathrm{Tg}}\right)$ mice.

Eight independent $S H 2 B 1^{T g}$ founders were obtained. To examine the expression of the $S H 2 B 1$ transgene, brain extracts were prepared from WT control and $S H 2 B 1^{\mathrm{Tg}}$ mice, immunoprecipitated with $\alpha$-SH2B1 and immunoblotted with $\alpha$-Myc. Recombinant SH2B1 $\beta$ was detected in $S H 2 B 1^{\text {Tg }}$ but not 
A

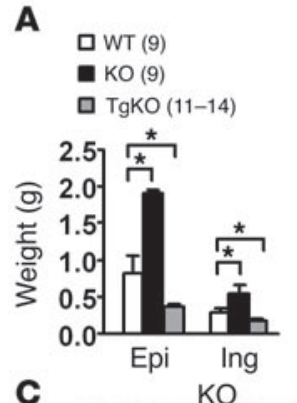

C
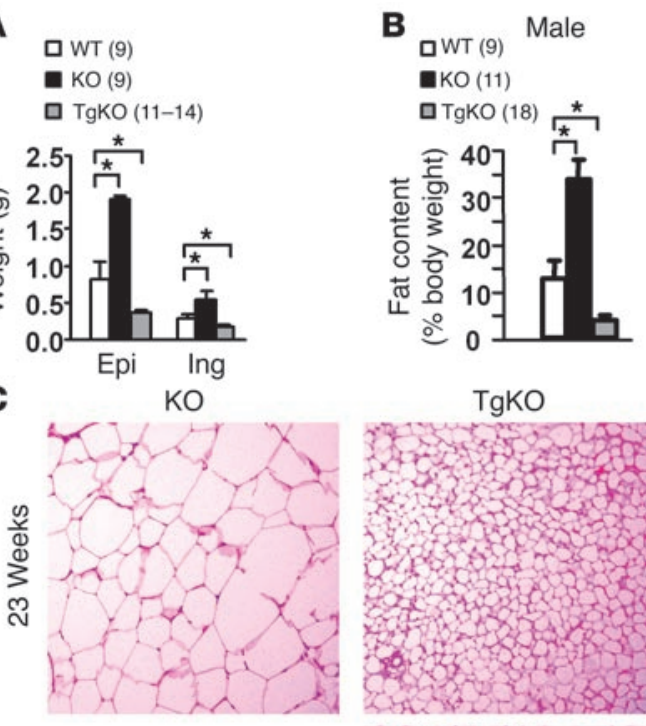

TgKO
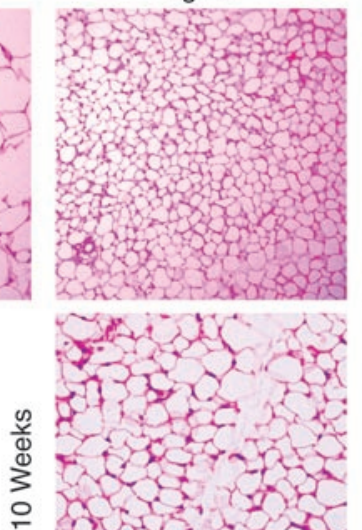

D

\section{$\mathbf{E}$}

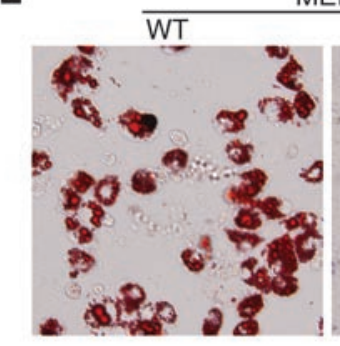

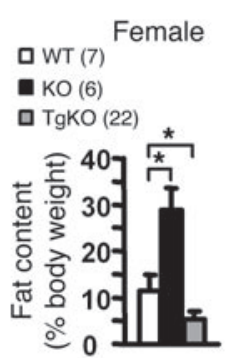

WT
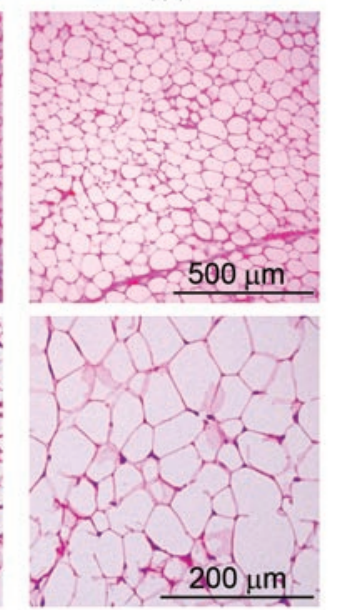

EF
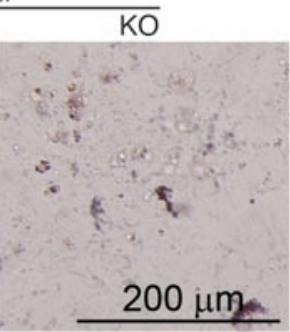

\section{Figure 2}

Neuronal and adipose SH2B1 have opposite effects on adiposity. (A) Weight of epididymal

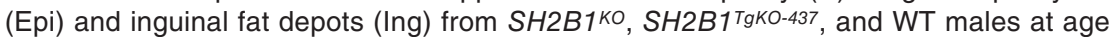
23-24 weeks. (B) Whole body fat content in SH2B1KO, SH2B1TgKO-437, and WT mice. (C) Representative H\&E staining of epididymal fat depots from SH2B1KO, SH2B1TgKO-437, and WT males at age 23 weeks (upper panels) or from $\mathrm{SH} 2 \mathrm{~B} 1$ TgKO-437 and WT males at age 10 weeks (lower panels). (D) 3T3-L1 preadipocytes were differentiated into adipocytes for 0, 3, 6 , or 10 days. Cell extracts were immunoprecipitated with $\alpha-\mathrm{SH} 2 \mathrm{~B} 1$ and immunoblotted with $\alpha$-SH2B1 (upper panel). Cell extracts were also immunoblotted with anti- $\beta$-actin antibodies (lower panel). (E) WT and SH2B1 ${ }^{\mathrm{KO}}$ MEF primary cultures were subjected to adipocyte differentiation for 10 days. Differentiated cells were stained with oil red $O$. ${ }^{\star} P<0.05$.

WT mice (Figure 1C). All 8 SH2B1'Tg lines expressed similar levels of recombinant SH2B1 $\beta$ (data not shown).

Two independent SH2B1 ${ }^{\text {Tg }}$ lines (SH2B1 ${ }^{\text {Tg-437 }}$ and SH2B1Tg-407) were crossed with heterozygous $S H 2 B 1$-knockout mice to generate compound mutant mice ( $S H 2 B 1^{\text {TgKOO-437 }}$ and $S H 2 B 1^{T g K O}-407$ ) that were heterozygous for the $S H 2 B 1 \beta$-transgenic allele and homozygous for the $S H 2 B 1^{K O}$ allele. The expression of recombinant SH2B $1 \beta$ was similar in $S H 2 B 1^{T-437}$ and $S H 2 B 1^{T r}-407$ mice and restricted to neural tissues in both $S H 2 B 1^{T-437}$ and $S H 2 B 1^{T g-407}$ mice (data not shown). To compare the expression levels of the SH2B1 transgene and endogenous SH2B1 gene, brain extracts corrected hyperlipidemia in $S H 2 B 1{ }^{\circ K O}$ mice

(Figure 1G). SH2B1 ${ }^{K O}$ mice had hepatic steatosis as revealed by an enlarged liver mass and significantly increased hepatic lipid content (Figure 1H). Neuron-specific restoration of SH2B1 largely reversed hepatic steatosis in $\mathrm{SH} 2 \mathrm{~B} 1^{\mathrm{TgKO}}$ mice (Figure $1 \mathrm{H}$ ).

Neuronal and adipose SH2B1 exert opposite effects on adiposity. To further analyze adiposity, individual white adipose depots were weighed, and whole body fat content was measured by the dualenergy $x$-ray absorptiometry (DEXA) method. Systemic deletion of SH2B1 markedly increased the mass of both epididymal and inguinal fat depots in $\mathrm{SH} 2 \mathrm{~B} 1^{\mathrm{KO}}$ mice (Figure $2 \mathrm{~A}$ ). Whole body fat content was increased by approximately 2.6 -fold in male and approximate- 
A
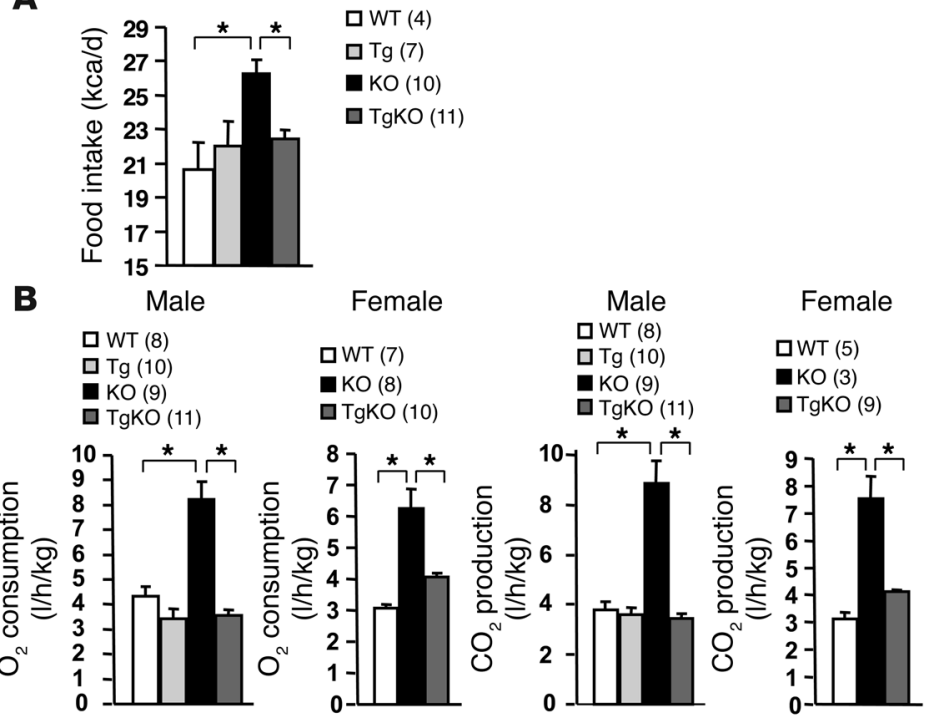

Figure 3

Neuron-specific restoration of SH2B1 corrects energy imbalance in SH2B1 ${ }^{\mathrm{KO}}$ mice. (A) Food intake in WT, SH2B1 ${ }^{\mathrm{Tg}}, \mathrm{SH} 2 \mathrm{~B} 1^{\mathrm{KO}}$, and $\mathrm{SH} 2 \mathrm{~B} 1^{\mathrm{Tg} K \mathrm{KO}-437}$ mice at age 14-15 weeks. (B) $\mathrm{O}_{2}$ consumption and $\mathrm{CO}_{2}$ production in WT, $\mathrm{SH} 2 \mathrm{~B} 1^{\mathrm{Tg}}$, $S H 2 B 1^{K O}$, and $S H 2 B 1^{T g K O}-437$ mice at age $16-17$ weeks. ${ }^{*} P<0.05$.

ly 2.5 -fold in female $S H 2 B 1^{K O}$ mice (Figure $2 \mathrm{~B}$ ). Neuron-specific restoration of SH2B1 (to endogenous levels) completely reversed the elevation in fat mass in SH2B1 $1^{T_{g} K O}$ mice (Figure 2, A and B). Histological examination of epididymal fat depots revealed that systemic deletion of SH2B1 markedly increased the size of individual adipocytes in $S H 2 B 1^{K O}$ mice; neuron-specific restoration of SH2B1 completely reversed adipocyte hypertrophy in SH2B1 ${ }^{\mathrm{g} K O}$ mice (Figure 2C, upper panels). These data demonstrated that neuronal SH2B1 negatively controls adiposity in animals.

Compared with those in age-matched WT control mice, both total fat mass and the size of individual white adipocytes were significantly reduced in $S H 2 B 1^{T g K O}$ mice, which lacked SH2B1 in adipose tissue (Figure 2, A-C). These results suggest that adipose SH2B1 may be involved in adipocyte growth and/or differentiation. To obtain additional evidence, we examined SH2B1 expression during 3T3-L1 adipocyte differentiation. Cell extracts were immunoprecipitated with $\alpha$-SH2B1 and immunoblotted with $\alpha$-SH2B1. 3T3-L1 preadipocytes expressed low levels of endogenous SH2B1. SH2B1 expression increased progressively during adipocyte differentiation, reaching maximal levels within 6 days after the induction of differentiation (Figure 2D). The effect of SH2B1 deficiency on adipocyte differentiation was examined using mouse embryonic fibroblasts (MEFs). Both WT and $S H 2 B 1^{K O}$ MEF primary cultures were subjected to an in vitro adipocyte differentiation treatment and then stained with oil red O to identify differentiated adipocytes. Deletion of SH2B1 impaired the ability of MEFs to differentiate into adipocytes (Figure 2E). These results suggest that adipose SH2B1 is involved in adipogenesis in a cell-autonomous fashion. However, neuronal SH2B1 may play a dominant role over adipose SH2B1 in controlling adiposity in vivo; therefore, deletion of SH2B1 in both the brain and adipose tissue results in adipocyte hypertrophy and obesity in $\mathrm{SH} 2 \mathrm{~B} 1^{\mathrm{KO}}$ mice.
Neuron-specific restoration of $S H 2 B 1$ reverses energy imbalance in SH2B1 ${ }^{\mathrm{KO}}$ mice. Systemic deletion of SH2B1 resulted in hyperphagia, markedly increasing food intake in $S H 2 B 1^{K O}$ mice (Figure $3 \mathrm{~A}$ ). $S H 2 B 1^{K O}$ mice also had significantly elevated energy expenditure, as revealed by significantly increased $\mathrm{O}_{2}$ consumption and $\mathrm{CO}_{2}$ production (Figure 3B). A previous report showed that energy intake still exceeds energy expenditure in this setting, resulting in obesity in $\mathrm{SH} 2 \mathrm{~B} 1^{\mathrm{KO}}$ mice (45). Neuron-specific restoration of SH2B1 largely corrected hyperphagia and markedly reduced energy expenditure in $S H 2 B 1^{\text {TgKO }}$ mice (Figure 3, $\mathrm{A}$ and $\mathrm{B})$. These results suggest that SH2B1 in the brain controls body weight and adiposity by inhibiting both energy intake and expenditure.

Newron-specific restoration of $\mathrm{SH} 2 \mathrm{~B} 1$ corrects leptin resistance and bypothalamic neuropeptide expression in $\mathrm{SH} 2 \mathrm{~B} 1^{\mathrm{KO}}$ mice. Systemic deletion of SH2B1 dramatically increased plasma leptin levels (hyperleptinemia) in both fasted and fed $S H 2 B 1^{K O}$ mice, a hallmark of leptin resistance (Figure 4A). Neuron-specific restoration of $\mathrm{SH} 2 \mathrm{~B} 1$ expression completely reversed hyperleptinemia in SH2B1 ${ }^{\mathrm{T} K K O}$ mice (Figure 4A). Acute exogenous leptin treatment markedly reduced body weight and food intake in WT mice, as predicted (Figure 4B and data not shown). Systemic deletion of SH2B1 abolished these physiological responses to leptin in $\mathrm{SH} 2 \mathrm{~B} 1^{\mathrm{KO}}$ mice, including leptininduced reduction in body weight (Figure 4B). Neuron-specific restoration of SH2B1 fully rescued the ability of leptin to reduce body weight in $S H 2 B 1^{T_{g} K O}$ mice (Figure 4B). These data indicate that neuron-specific restoration of SH2B1 (to endogenous levels) is sufficient to rescue leptin resistance in $\mathrm{SH} 2 \mathrm{~B} 1^{\mathrm{KO}}$ mice.

To examine leptin signaling in the hypothalamus, mice were fasted overnight and injected intraperitoneally with leptin $(1 \mathrm{mg} / \mathrm{kg}$ body weight). Hypothalamic extracts were immunoblotted with anti-phospho-STAT3 antibodies that specifically recognize phosphorylated and active STAT3. Systemic deletion of SH2B1 significantly impaired leptin-stimulated phosphorylation of STAT3 (Figure 4C). Neuron-specific restoration of SH2B1 increased leptin-stimulated phosphorylation of hypothalamic STAT3 in SH2B1 ${ }^{\mathrm{Tg} K O}$ mice to levels similar to those in age-matched WT controls, suggesting that neuronal SH2B1 may cell-autonomously enhance leptin signaling in the hypothalamus (Figure 4C).

Leptin inhibits the expression of orexigenic neuropeptide Y (NPY) and agouti-related protein (AgRP) and stimulates the expression of anorexigenic POMC in the arcuate nucleus of the hypothalamus $(1,3,50)$. NPY and AgRP promote positive energy imbalance, whereas $\alpha$-melanocyte-stimulating hormone ( $\alpha$-MSH), a proteolytic product of POMC, promotes negative energy imbalance $(2,3,51)$. The abundance of hypothalamic NPY, AgRP, and POMC mRNA was measured using quantitative real-time PCR assays and normalized to the expression of $\beta$-actin. Systemic deletion of SH2B1 markedly increased NPY and AgRP but not POMC expression in $\mathrm{SH} 2 \mathrm{~B} 1^{\mathrm{KO}}$ mice (Figure 4D). Neuron-specific restoration of SH2B1 dramatically reduced NPY expression in $S H 2 B 1^{T S K O}$ mice to levels similar to those in WT controls (Figure 4D). AgRP expression was also significantly reduced in $S H 2 B 1^{T g K O}$ mice, but to a lesser extent (Figure 4D). Neuronal SH2B1 may inhibit the expression of orexigenic NPY and AgRP presumably by enhancing leptin signaling in the hypothalamus.

Neuron-specific overexpression of SH2B1 protects against HFD-induced leptin resistance and obesity. To determine whether a modest increase in neuronal SH2B1 expression protects against leptin resistance 
A

\begin{tabular}{|c|c|c|}
\hline Fasted & \multicolumn{2}{|c|}{ Fed } \\
\hline Male & Male & Female \\
\hline 口 WT (8) & 口WT (5) & $\square W T(9)$ \\
\hline $\begin{array}{l}4 \mathrm{Tg}(8) \\
\mathrm{KO}(10)\end{array}$ & $\begin{array}{l}\boldsymbol{G} \text { KO (10) } \\
\text { TgKO (12) }\end{array}$ & $\begin{array}{l}\mathbf{B} \mathrm{KO}(6) \\
\mathbf{T g K O}(10)\end{array}$ \\
\hline
\end{tabular}
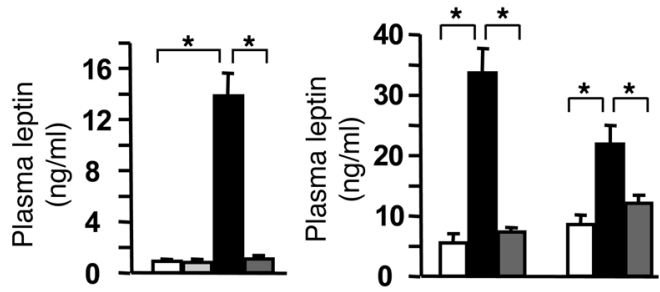

C

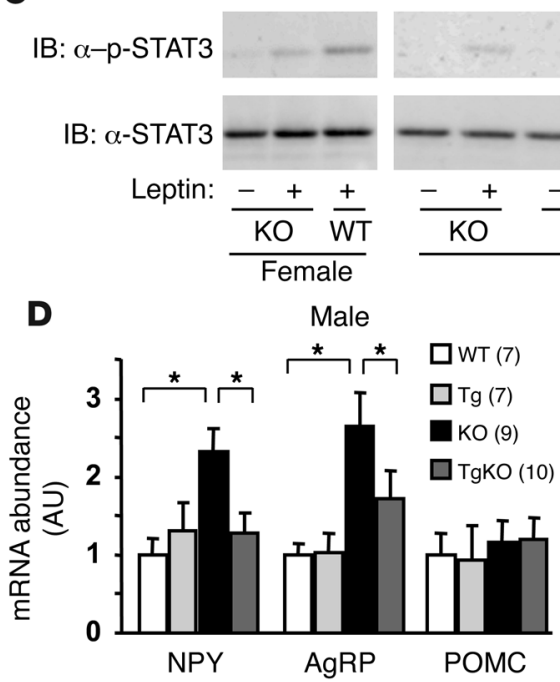

B $-\square-$ WT-PBS (3) - O. - KO-PBS (4)

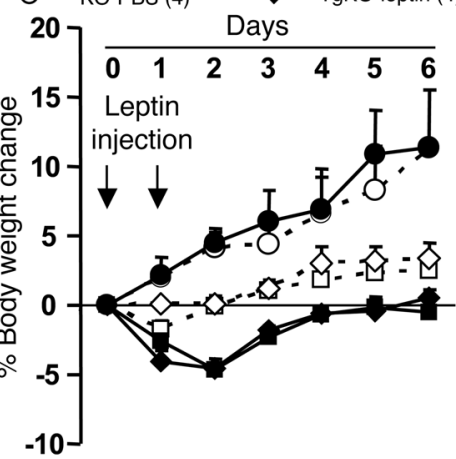

$\rightarrow-$ KO-leptin (4)

$-\diamond-$ TgKO-PBS (4) $\neg$ TgKO-leptin (4)

4)

Neuron-specific restoration of SH2B1 reverses leptin resistance in $\mathrm{SH} 2 \mathrm{~B} 1 \mathrm{KO}$ mice. (A) Plasma leptin levels in fasted (10 weeks old) and fed ad libitum (13 weeks old) mice. (B) Male mice (9 weeks old) were housed individually and injected intraperitoneally with leptin ( $2 \mathrm{mg} / \mathrm{kg}$ body weight) or PBS (control) twice a day (6:00 pm and 12:00 am). Body weight was monitored both before and after the injection. Changes in body weight were calculated as a percentage of the initial values prior to the injection. (C) Female (right panel: 6 weeks old) and male (middle panel: 12 weeks old; right panel: 9 weeks old) mice were fasted for 24 hours and injected intraperitoneally with leptin ( $1 \mathrm{mg} / \mathrm{kg}$ of body weight) or PBS as control. Hypothalamic extracts were prepared 45 minutes after injection and immunoblotted with $\alpha-p$-STAT3 or $\alpha$-STAT3. Each lane represents a combination of 2 hypothalami. (D) Hypothalamic RNA was prepared from males (22 weeks old, fasted overnight). NPY, AgRP, and POMC mRNA levels were measured using quantitative real-time PCR and normalized to the expression of $\beta$-actin. ${ }^{*} P<0.05$.

and obesity, $S H 2 B 1^{T g}$ and WT littermates were fed an HFD. Body weight and fat content were similar in $\mathrm{SH} 2 \mathrm{~B} 1^{\mathrm{Tg}}$ and WT littermates (Figure 5, A and B). However, blood leptin levels were significantly reduced, by $58 \%$, in $\mathrm{SH} 2 \mathrm{~B} 1^{\mathrm{Tg}}$ mice, suggesting an increase in leptin sensitivity in $\mathrm{SH} 2 \mathrm{~B} 1^{\mathrm{Tg}}$ mice (Figure $5 \mathrm{C}$ ). These results suggest that while a modest increase in neuronal SH2B1 expression mildly increases leptin sensitivity, this is insufficient to protect against $\mathrm{HFD}$-induced obesity in $\mathrm{SH} 2 \mathrm{~B} 1^{\mathrm{Tg}}$ mice.

To increase neuronal SH2B1 expression, $S H 2 B 1^{\text {Tg }}$ mice were bred to generate homozygous SH2B1-transgenic mice ( $S H 2 B 1^{\mathrm{Tg} / T g}$ ). Two independent $S H 2 B 1^{T g} / \mathrm{Tg}$ lines ( $S H 2 B 1^{\mathrm{Tg} / \mathrm{Tg}-437}$ and $S H 2 B 1^{\mathrm{Tg} / \mathrm{Tg}-407}$ ) were obtained. To examine the $S H 2 B 1$ transgene expression, brain extracts were immunoprecipitated with $\alpha$-SH2B 1 and immunoblotted with $\alpha$-Myc to detect Myc-tagged recombinant $\mathrm{SH} 2 \mathrm{~B} 1 \beta$. The expression of the $S H 2 B 1 \beta$ transgene was significantly higher in $S H 2 B 1^{T g / T g}$ than in $S H 2 B 1^{T g K O-437}$ and $S H 2 B 1^{T g-407}$ mice (heterozygous for the $S H 2 B 1 \beta$ transgene) (Figure 6A). Neuron-specific overexpression of SH2B1 did not have an obviously deleterious effect on the overall health of $\mathrm{SH} 2 \mathrm{~B} 1^{\mathrm{Tg} / \mathrm{Tg}}$ mice.

To determine the dosage effect of neuronal SH2B1 on leptin sensitivity and adiposity, body weight and blood leptin levels were measured. Body weight markedly decreased in both $S H 2 B 1^{T g} / T_{g}-437$ and SH2B1 ${ }^{\mathrm{Tg} / \mathrm{Tg}-407}$ compared with WT control mice fed normal chow (Figure 6B, left panel). Fasting plasma leptin levels were significantly lower in $S H 2 B 1^{T g} T^{T g}$ than in WT control mice (Figure 6D).
Mice were fed an HFD at 7 weeks of age. HFD markedly increased both body weight and fat content in WT mice, whereas both SH2B $1^{\text {Tg } / T g-407}$ and SH2B1 $1^{\text {Tg } / T g-437}$ mice were resistant to HFD-induced obesity (Figure 6, B, right panel, and C). HFD induced severe hyperleptinemia (a hallmark of leptin resistance) in WT mice, increasing fasting blood leptin levels by 26 -fold; in contrast, plasma leptin levels were only mildly elevated in HFD-fed SH2B1 $1^{\text {TS }}$ Tg mice. Neuronal overexpression of SH2B1 reduced blood leptin levels by $98 \%$ in SH2B1 $1^{T g} / T_{g}-407$ and $92 \%$ in SH2B1 $1^{\text {Tg } / T_{g}-437}$ compared with WT control mice (Figure $6 \mathrm{D}$, right panel). Since the 2 lines of $S H 2 B 1^{\mathrm{Tg} / \mathrm{Tg}}$ mice were similarly protected against HFD-induced leptin resistance and obesity, overexpression of neuronal SH2B1, rather than other mutations derived from the random insertion of the SH2B1 transgene, enhances leptin sensitivity in $S H 2 B 1^{T / T} / \mathrm{Tg}$ mice.

To avoid the complete disruption of a gene by the transgenic inser-

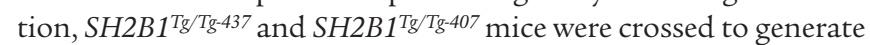

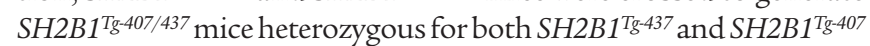
alleles. The expression levels of recombinant SH2B1 $\beta$ were similar in $S H 2 B 1^{T-407 / 437}$ and $S H 2 B 1^{T g / T g-437}$ or $S H 2 B 1^{\text {Tg/Tg-407 }}$ mice but higher in $S H 2 B 1^{T g-407 / 437}$ than in heterozygous $S H 2 B 1^{T g}$ mice (Figure 6A). Importantly, $S H 2 B 1^{T g-407 / 437}$ mice were protected against HFD-induced obesity to a similar extent as were $S H 2 B 1^{T g} / \mathrm{Tg}-407$ and $\mathrm{SH} 2 \mathrm{~B} 1^{\mathrm{Tg} / \mathrm{Tg}-437}$ mice (Figure 6, B, right panel, and C). Blood leptin levels were also reduced by $97 \%$ in $\mathrm{SH} 2 \mathrm{~B} 1^{\mathrm{Tg}-407 / 437}$ mice compared with WT mice (Figure 6D, right panel). 
A

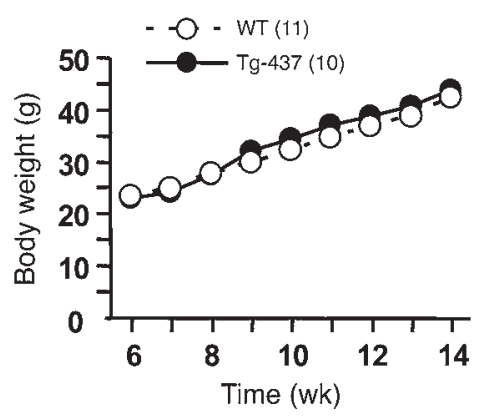

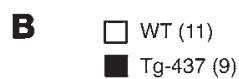

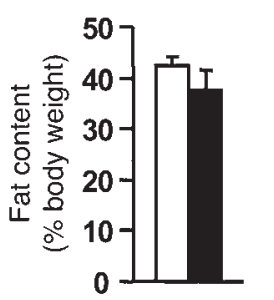

C

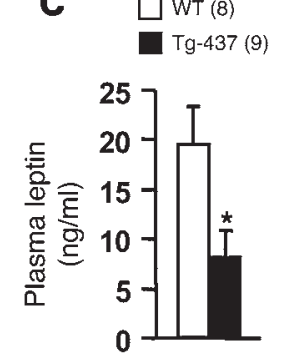

Figure 5

Neuronal SH2B1 increases leptin sensitivity. (A) SH2B1Tg-437 males and WT littermates were fed an HFD at age 7 weeks, and body weight was monitored weekly. (B) Fat content of SH2B1 ${ }^{\text {Tg-437 }}$ males and WT littermates fed an HFD for 9 weeks. (C) Plasma leptin levels in SH2B1 ${ }^{\text {Tg-437 }}$ males and WT littermates fed an HFD for 10 weeks. ${ }^{\star} P<0.05$.
Neuron-specific restoration of $S H 2 B 1$ reverses peripheral insulin resistance and glucose intolerance in $\mathrm{SH} 2 \mathrm{~B} 1^{\mathrm{KO}}$ mice. $\mathrm{SH} 2 \mathrm{~B} 1$ binds directly to the insulin receptor, thereby enhancing the activation of the insulin receptor and multiple downstream pathways in cultured cells $(44,52)$. Systemic deletion of SH2B1 results in severe insulin resistance and type 2 diabetes (44-46). However, it is unclear whether SH2B1 enhances insulin sensitivity directly by promoting insulin signaling in the liver, skeletal muscle, and/or adipose tissue or indirectly by reducing adiposity through its action in the brain.

Insulin sensitivity and glucose metabolism were compared in $S H 2 B 1^{K O}$ mice (which completely lack SH2B1 in all tissues) and $S H 2 B 1^{T g K O}$ mice (which only express $\mathrm{SH} 2 \mathrm{~B} 1$ in neural tissue).
$S H 2 B 1^{K O}$ mice developed severe hyperglycemia and hyperinsulinemia, hallmarks of insulin resistance (Figure 7A). Fasting plasma insulin levels increased by more than 26 -fold in $S H 2 B 1^{K O}$ compared with age-matched WT controls. Neuron-specific restoration of SH2B1 corrected both hyperglycemia and hyperinsulinemia in $S H 2 B 1^{T g K O}$ mice (Figure 7A).

To further examine peripheral insulin sensitivity, glucose and insulin tolerance tests (GTTs and ITTs) were performed. In GTTs, mice were fasted overnight and injected intraperitoneally with D-glucose ( $2 \mathrm{~g} / \mathrm{kg}$ body weight), and blood glucose levels were measured at various time points after glucose injection. Compared with WT controls, $S H 2 B 1^{K O}$ mice were severely intolerant to exogenous

\section{Figure 6}

Neuron-specific overexpression of SH2B1 dose-dependently reduces HFD-induced leptin resistance and obesity. (A) Brain extracts were prepared from WT, SH2B1TgKO-437, SH2B1Tg/Tg-437, SH2B1Tg-407, SH2B1Tg/Tg-407, and $S H 2 B 1^{T g-407 / 437}$ males, immunoprecipitated with $\alpha-S H 2 B 1$, and immunoblotted with $\alpha$-Myc. Extracts were also immunoblotted with anti$\beta$-actin. Each lane represents a sample from 1 mouse. (B) Growth curves for male mice (WT,

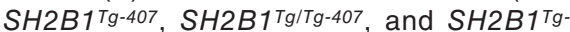
$407 / 437$ ) fed normal chow or HFD as indicated. (C) Fat content in male mice (16 weeks old) fed an HFD for 9 weeks. (D) Fasting plasma leptin levels in male mice fed standard chow (WT and SH2B1 ${ }^{\text {Tg/Tg-437; }} 117$ weeks old) or HFD for 7 weeks (WT, SH2B1'Tg/Tg-407, SH2B1Tg/Tg-437, and $S H 2 B 1^{T g-407 / 437} ; 14$ weeks old). ${ }^{*} P<0.05$.

A

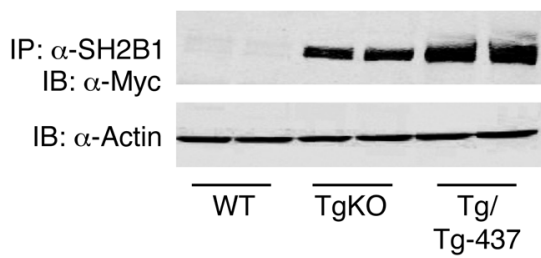

B

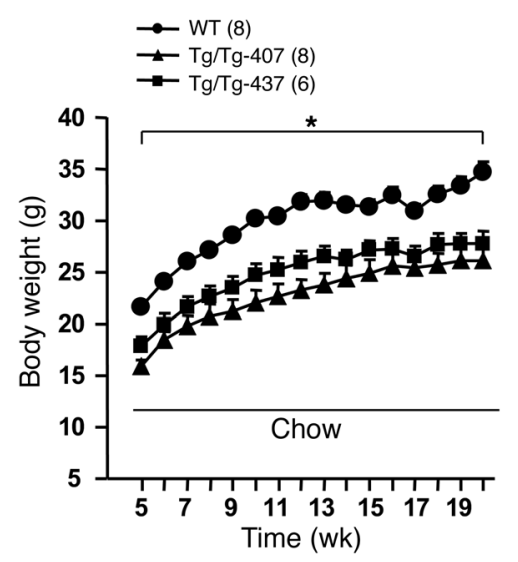

C

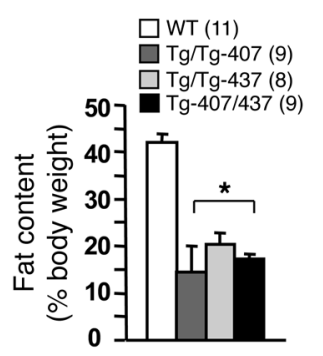

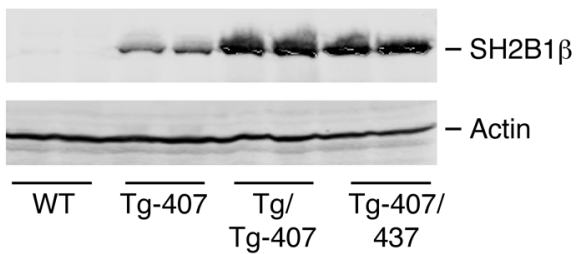
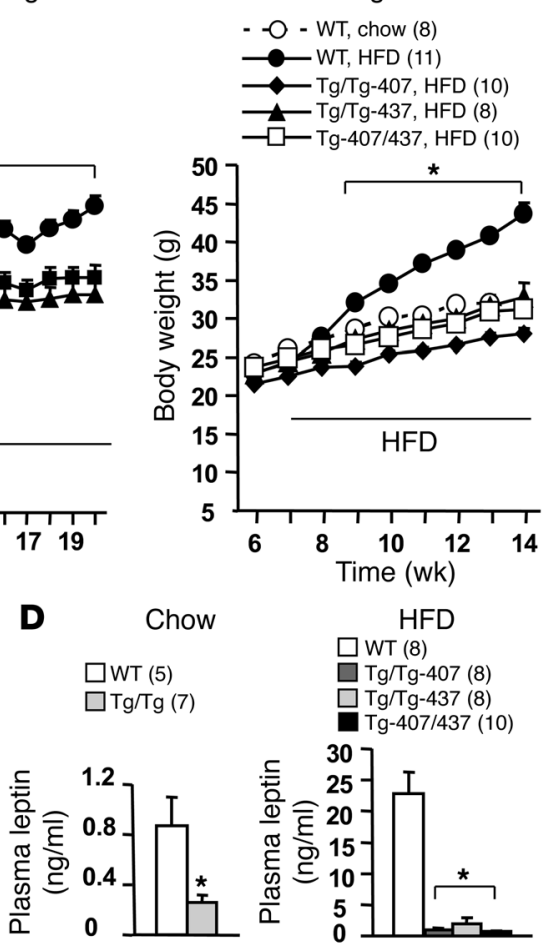
A

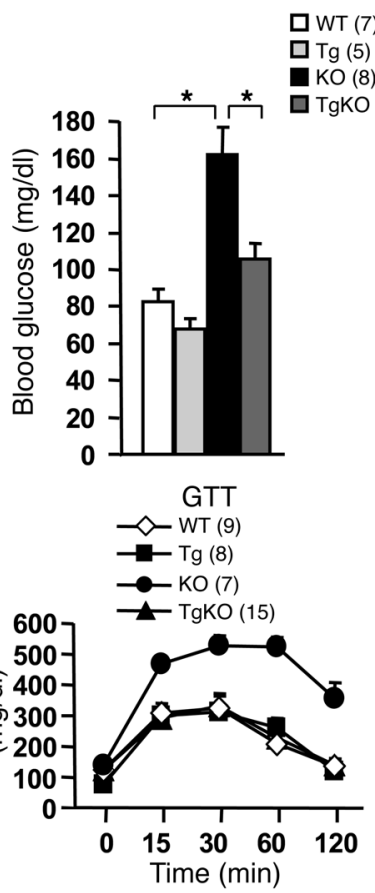

$\square$ WT (7)

$\mathrm{KO}(8)$
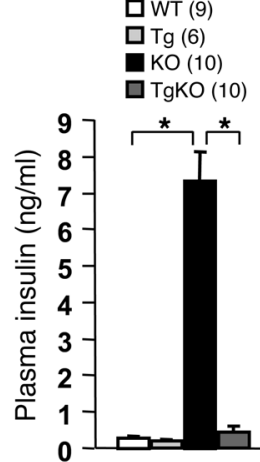

C

ITT
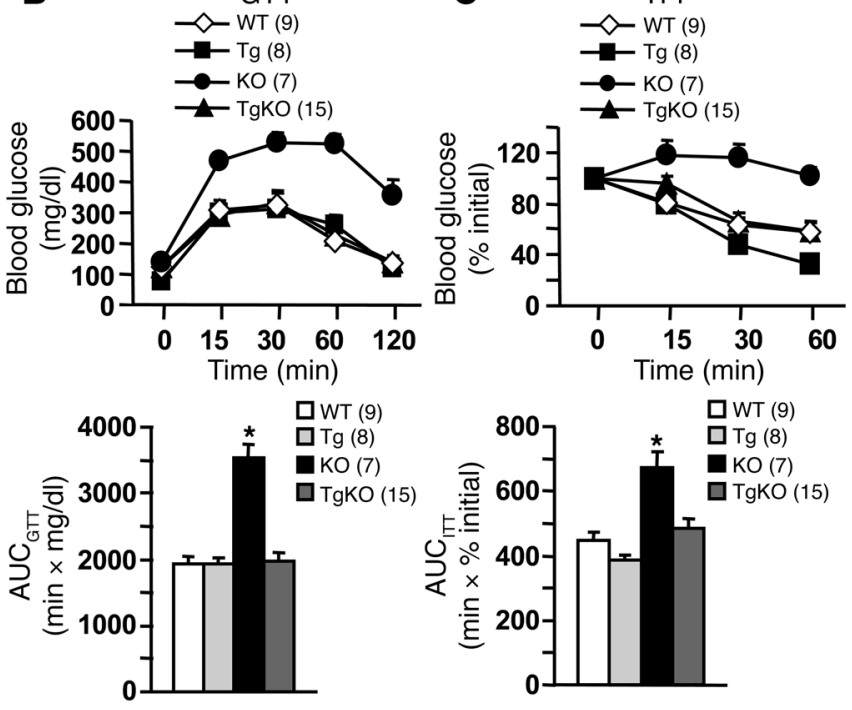

glucose as revealed by a marked increase in both the magnitude and duration of the elevation of blood glucose in response to glucose injection (Figure 7B). Neuron-specific restoration of SH2B1 (to endogenous levels) fully rescued glucose intolerance in $\mathrm{SH} 2 \mathrm{~B} 1^{\mathrm{TgKO}}$ mice (Figure 7B). In ITTs, exogenous insulin (1 U/kg body weight) failed to decrease blood glucose levels in $\mathrm{SH} 2 \mathrm{~B} 1^{\mathrm{KO}}$ mice; in contrast, insulin-induced reductions in blood glucose levels were comparable in $S H 2 B 1^{T g K O}$ and WT mice (Figure $7 \mathrm{C}$ ). The area under the curve (AUC) significantly increased in $\mathrm{SH} 2 \mathrm{~B}^{\mathrm{KO}}$ mice in both GTTs and ITTs, and this was reversed by neuron-specific restoration of SH2B1 in SH2B1 $1_{g K O}$ mice (Figure 7, B and C). Blood glucose and plasma insulin levels and glucose tolerance were similar in $S H 2 B 1^{T g}$ and WT mice (Figure 7, A and B). Therefore, neuronal SH2B1 rather than SH2B1 expressed in the liver, muscle, and adipose tissue controls peripheral insulin sensitivity and glucose metabolism under these experimental conditions.

\section{Discussion}

The SH2B family contains 3 members (SH2B1, SH2B2, and $\mathrm{SH} 2 \mathrm{~B} 3$ ) that contain a conserved $\mathrm{PH}$ and $\mathrm{SH} 2$ domain. SH2B1 is believed to mediate cell signaling in response to multiple hormones, growth factors, and cytokines, including GH, leptin, insulin, IGF-1, PDGF, FGF, nerve growth factor, brain-derived neurotrophic factor, and glial cell-derived neurotrophic factor $(29,32-42)$. Systemic deletion of SH2B1 resulted in energy imbalance, morbid obesity, and severe glucose intolerance, suggesting

\section{Figure 7}

Neuron-specific restoration of $\mathrm{SH} 2 \mathrm{~B} 1$ rescues insulin resistance and glucose intolerance in SH2B1KO mice. (A) Blood glucose in fasted males at age 17 weeks and plasma insulin in fasted males at age 21 weeks. GTTs (B) and ITTs (C) in males at age of 21 weeks. The area under the curve (AUC) was calculated in both GTTs and ITTs using the trapezoidal rule. ${ }^{*} P<0.05$.

that $\mathrm{SH} 2 \mathrm{~B} 1$ has a unique function in the regulation of body weight and glucose metabolism, which cannot be compensated for by SH2B2 and SH2B3. SH2B1 is ubiquitously expressed in both neuronal and non-neuronal tissues, including the brain, liver, skeletal muscle, and adipose tissue. All these tissues are involved in the regulation of adiposity and glucose metabolism. Interestingly, neuron-specific restoration of recombinant SH2B1 in $S H 2 B 1^{T S K O}$ mice corrected the hyperphagia, obesity, hyperglycemia, and glucose intolerance observed in $\mathrm{SH} 2 \mathrm{~B} 1^{\mathrm{KO}}$ mice. Moreover, neuron-specific overexpression of SH2B1 dose-dependently protected against HFD-induced obesity. These observations suggest that endogenous $\mathrm{SH} 2 \mathrm{~B} 1$ in the brain plays a key role in controlling body weight and glucose homeostasis. Multiple forms of SH2B1 were expressed in the brain; however, neuron-specific restoration of recombinant $\mathrm{SH} 2 \mathrm{~B} 1 \beta$ alone was sufficient to reverse obese and glucose-intolerant phenotypes observed in $\mathrm{SH} 2 \mathrm{~B} 1^{\mathrm{KO}}$ mice, suggesting that $\mathrm{SH} 2 \mathrm{~B} 1 \beta$ and other isoforms of $\mathrm{SH} 2 \mathrm{~B} 1$ in the brain similarly regulate energy and glucose metabolism.

Neuronal SH2B1 regulates energy and glucose metabolism at least in part by enhancing leptin sensitivity in the brain, particularly in the hypothalamus. Systemic deletion of SH2B1 resulted in severe leptin resistance as demonstrated by marked hyperleptinemia, significantly reduced physiological responses to leptin (e.g., leptin-induced anorexia and inhibition of hypothalamic NPY and AgRP expression), and impaired leptin signaling in the hypothalamus. Leptin resistance precedes the onset of obesity in $S H 2 B 1^{K O}$ mice (45). Leptin regulates energy metabolism and body weight mainly by activating LEPRb in the brain. Neuron-specific restoration of SH2B1 fully rescued not only leptin resistance but also obesity in $\mathrm{SH} 2 \mathrm{~B} 1^{\operatorname{TgKO}}$ mice, which do not express $\mathrm{SH} 2 \mathrm{~B} 1$ in peripheral tissues (e.g., muscle, adipose tissue, and liver). A modest increase in neuronal SH2B1 expression reduced blood leptin levels by $58 \%$ in $\mathrm{SH} 2 \mathrm{~B} 1^{\mathrm{Tg}}$ mice, which were heterozygous for the SH2B1 transgene, compared with WT littermates fed an HFD. Further increases in neuronal SH2B1 expression reduced blood leptin levels to a much higher extent in $S H 2 B 1^{T g / T g-407}$ (by 98\%), SH2B1 ${ }^{T g} / \operatorname{Tg}^{-437}$ (by 92\%), and SH2B1 $1^{T g-407 / 437}$ (by 97\%) mice. After normalization to total fat mass, blood leptin levels were still significantly reduced in $\mathrm{SH} 2 \mathrm{~B} 1^{\mathrm{Tg} / \mathrm{Tg}-407}$ (by 93\%), SH2B1 $1^{\text {Tg } / T g-437}$ (by $93 \%$ ), and $S H 2 B 1^{T g-407 / 437}$ (by $92 \%$ ) mice. Therefore, neuronal SH2B1 improves leptin sensitivity in a dose-dependent manner. More importantly, SH2B1 Tg/Tg-407, SH2B $1^{\mathrm{Tg} / \mathrm{Tg}-437}$, and $\mathrm{SH} 2 \mathrm{~B} 1^{\mathrm{Tg}-407 / 437}$ mice were protected against HFD-induced obesity, supporting the idea that neuronal SH2B1 may negatively regulate adiposity at least in part by enhancing leptin sensitivity. However, these studies do not exclude the possibility that neuronal SH2B1 may regulate energy and glucose metabolism by additional leptinindependent mechanisms. SH2B1 directly enhances insulin signaling $(44,52)$. Insulin regulates energy metabolism and body weight by activating its receptor in the brain $(53,54)$. SH2B1 may also regulate energy and glucose metabolism by enhancing insulin sensitivity in the brain. 
Neuronal SH2B1 increases leptin sensitivity at least in part by directly enhancing leptin signaling in LEPRb-expressing neurons in a cell-autonomous manner. SH2B1 directly binds via its SH2 domain to phosphorylated Tyr813 in JAK2, enhancing JAK2 activation in cultured cells $(27,29,55-57)$. Deletion of SH2B1 impairs leptin-stimulated activation of hypothalamic JAK2 in $S H 2 B 1^{K O}$ mice (45). Systemic deletion of SH2B1 markedly reduced leptinstimulated phosphorylation of hypothalamic STAT3 (a main substrate of JAK2), which was fully rescued by neuron-specific restoration of SH2B1 in $\mathrm{SH} 2 \mathrm{~B} 1^{\mathrm{TgKO}}$ mice. Moreover, $\mathrm{SH} 2 \mathrm{~B} 1$ binds simultaneously to both JAK2 and IRS2, thereby promoting leptinstimulated tyrosine phosphorylation of IRS2, presumably by both enhancing JAK2 activation and recruiting IRS2 to JAK2 (58). Disruption of SH2B1 blocks leptin-stimulated tyrosine phosphorylation of hypothalamic IRS2 (45). IRS2 is an upstream activator of the PI3K pathway, which is required for leptin regulation of energy metabolism $(16,17,59)$. Interestingly, PTP1B inhibits leptin signaling by inhibiting JAK2 activation and JAK2-mediated pathways, which is reversed by SH2B1 $(27,45,56)$. Therefore, leptin sensitivity appears to be regulated by a balance between positive (e.g., SH2B1) and negative regulators (e.g., PTP1B and SOCS3) in LEPRb-expressing cells. JAK2 is likely to integrate signals from both intracellular positive (e.g., SH2B1) and negative modulators (e.g., PTP1B and SOCS3) in LEPRb-expressing neurons.

Leptin reduces body weight by both decreasing energy intake and increasing energy expenditure. Surprisingly, $S H 2 B 1^{K O}$ mice have a marked increase in both energy intake and expenditure in the presence of severe systemic leptin resistance. Neuron-specific restoration of SH2B1 reversed both leptin resistance and energy imbalance in $\mathrm{SH} 2 \mathrm{~B} 1^{\mathrm{TgKO}}$ mice. These results suggest that leptin regulates energy intake and expenditure by 2 distinct pathways in the brain. Consistent with this idea, melanocortin-4 receptor-expressing (MC4R-expressing) neurons in the paraventricular hypothalamus and/or the amygdala, which are directly innervated by hypothalamic LEPRb-neurons, control energy intake, whereas the MC4Rexpressing neurons in other areas control energy expenditure (60). Energy intake and expenditure may be controlled by 2 distinct subpopulations of LEPRb-expressing neurons. SH2B1 may cellautonomously enhance leptin signaling to a much higher degree in LEPRb-neurons controlling energy intake than in LEPRb-neurons controlling energy expenditure. Therefore, systemic deletion of SH2B1 may impair leptin sensitivity more severely in the LEPRbneurons controlling energy intake than in the LEPRb-neurons controlling energy expenditure. Compensatory hyperleptinemia may not overcome severe leptin resistance in the LEPRb-neurons controlling energy intake, resulting in hyperphagia in $S H 2 B 1^{K O}$ mice. Conversely, hyperleptinemia may be sufficient to overcome mild leptin resistance in the LEPRb-neurons controlling energy expenditure, resulting in increased energy expenditure in $\mathrm{SH} 2 \mathrm{~B} 1^{\mathrm{KO}}$ mice. However, neuronal SH2B1 may also regulate energy intake and expenditure by additional leptin-independent mechanisms.

Adipose SH2B1 may also be involved in the regulation of adiposity. SH2B1 expression was upregulated during adipocyte differentiation of 3T3-L1 cells. Deletion of SH2B1 impaired the ability of MEFs to differentiate into adipocytes in vitro. Moreover, SH2B1TgKO mice, which do not express SH2B1 in adipose tissue, had a significant reduction in both fat content and the size of individual white adipocytes. These results suggest that adipose SH2B1 may cellautonomously regulate adipocyte growth, differentiation, and/or function. SH2B1 binds to the insulin receptor, enhancing insulin signaling $(44,52)$. Insulin promotes adipogenesis; therefore, adipose $\mathrm{SH} 2 \mathrm{~B} 1$ may regulate adipogenesis by enhancing insulin signaling. However, disruption of both neuronal and adipose SH2B1 resulted in adipocyte hypertrophy and massive obesity in $\mathrm{SH} 2 \mathrm{~B} 1^{\mathrm{KO}}$ mice, suggesting that neuronal SH2B1 play a dominant role in controlling adipocyte differentiation and/or growth in vivo.

$\mathrm{SH} 2 \mathrm{~B} 1$ was abundantly expressed in peripheral insulin target tissues, including the liver, muscle, and adipose tissues. In cultured cells, SH2B1 binds via its $\mathrm{SH} 2$ domain to the insulin receptor, enhancing insulin signaling $(32,33,35,40,44,52)$. Systemic deletion of SH2B1 resulted in marked hyperglycemia, hyperinsulinemia, and glucose and insulin intolerance in $\mathrm{SH} 2 \mathrm{~B} 1^{\mathrm{KO}}$ mice, as expected. Surprisingly, neuron-specific restoration of SH2B1 fully rescued insulin resistance and glucose intolerance in $S H 2 B 1^{T g K O}$ mice, even though these mice still lack SH2B1 in the liver, muscle, and adipose tissue. These results suggest that central rather than peripheral SH2B1 is essential for regulating systemic insulin sensitivity and glucose homeostasis in mice fed normal chow. However, it is unclear whether peripheral SH2B1 deficiency in the liver, muscle, and adipose tissue exacerbates insulin resistance and glucose intolerance induced by an HFD and/or other cellular stress. The mechanisms of neuronal SH2B1 regulation of systemic insulin sensitivity and glucose metabolism remain largely unknown. First, neuronal SH2B1 negatively regulates adiposity, thus enhancing peripheral insulin sensitivity. Second, central leptin action increases peripheral insulin sensitivity by an adiposity-independent mechanism $(61,62)$. The PI3K pathway mediates leptin-induced and adiposity-independent enhancement of peripheral insulin sensitivity (62). $\mathrm{SH} 2 \mathrm{~B} 1$ promotes leptin-stimulated activation of the PI3K pathway $(45,58)$; therefore, neuronal SH2B1 may promote peripheral insulin sensitivity via a leptin-dependent and adiposity-independent mechanism. Third, central insulin action improves hepatic insulin sensitivity (63-66). Neuronal SH2B1 may promote peripheral insulin sensitivity and glucose metabolism by cell-autonomously enhancing insulin signaling in the hypothalamus.

In summary, systemic deletion of SH2B1 resulted in severe leptin resistance, insulin resistance, morbid obesity, and glucose intolerance in $S H 2 B 1^{K O}$ mice, all of which were largely reversed by neuronspecific restoration of SH2B1 in $S H 2 B 1^{T g K O}$ mice. Neuron-specific overexpression of $\mathrm{SH} 2 \mathrm{~B} 1$ protected against HFD-induced leptin resistance and obesity in a dose-dependent manner. Therefore, neuronal SH2B1 may serve as a potential target for therapeutic treatment of both obesity and type 2 diabetes.

\section{Methods}

Animal experiments. SH2B1-knockout mice (129Sv/C57BL/6 genetic background) were generated by homologous recombination as described previously (44). An SH2B1 transgene construct was prepared by inserting Myc-tagged full-length rat SH2B1 $\beta$ cDNA 3 '-prime of an NSE promoter/GH enhancer sequence. The $\mathrm{SH} 2 \mathrm{~B} 1$ transgene construct was microinjected into $\mathrm{F}_{2}$ mouse oocytes $(\mathrm{C} 57 \mathrm{BL} / 6 \times \mathrm{SJL})$ and surgically transferred to recipients in the University of Michigan Transgenic Animal Model Core to generate heterozygous SH2B1-transgenic $\left(S H 2 B 1^{T g}\right)$ animals. Genotyping was performed by PCRbased assays. Two independent $S H 2 B 1^{T g}$ lines (407 and 437) were inbred to generate homozygous $S H 2 B 1$-transgenic animals $\left(S H 2 B 1^{T g} / T g\right)$. In parallel experiments, these 2 lines were crossed with $S H 2 B 1$-knockout mice to generate $\mathrm{SH} 2 \mathrm{~B} 1$-transgenic and -knockout compound mutants $\left(\mathrm{SH} 2 \mathrm{~B} 1^{\mathrm{TgKO}}\right)$. Mice were housed on a 12-hour light/12-hour dark cycle in the Unit for Laboratory Animal Medicine (ULAM) at the University of Michigan, with free access to water and standard mouse chow (21\% kcal from fat) or an HFD (45\% kcal 
from fat). Animal experiments were conducted following protocols approved by the University Committee on the Use and Care of Animals (UCUCA).

Blood samples were collected from the tail vein and assayed for plasma insulin and leptin using rat insulin or mouse leptin ELISA kits (Crystal Chem Inc.), respectively. FFAs and TGs were measured using Wako NEFAC and Free Glycerol Reagent (Sigma-Aldrich), respectively.

For GTTs, mice were fasted overnight (approximately 16 hours), and D-glucose $(2 \mathrm{~g} / \mathrm{kg}$ of body weight) was injected intraperitoneally. Blood glucose was monitored at $0,15,30,60$, and 120 minutes after glucose injection. For ITTs, mice were fasted for 6 hours, and human insulin ( $1 \mathrm{IU} / \mathrm{kg}$ of body weight) was injected intraperitoneally. Blood glucose was monitored at $0,15,30$, and 60 minutes after insulin injection.

For histological analysis, adipose tissues were isolated and fixed in Bouins' solution (Sigma-Aldrich). Paraffin sections were prepared and stained with H\&E. Images were visualized using a BX51 microscope (Olympus) and captured using a DP70 Digital Camera (Olympus).

To examine leptin inhibition of food intake and weight gain, mice were housed individually with free access to food and water. Mice were injected with leptin ( $2 \mathrm{mg} / \mathrm{kg}$ body weight) or PBS (as control) twice daily (6:00 pm and 12:00 am) for 2 days. Food intake and body weight were monitored both before and after leptin injection.

To measure tissue TG, tissues were homogenized in chloroform/methanol (2:1) and incubated at room temperature for 4 hours. Tissue extracts were air dried, resuspended in $\mathrm{KOH}(3 \mathrm{M})$, incubated at $70^{\circ} \mathrm{C}$ for 1 hour, neutralized with $\mathrm{MgCl}_{2}$, and subjected to a TG assay as described above.

Measurements of energy expenditure. Metabolic rates were measured by indirect calorimetry (Windows Oxymax Equal Flow system; Columbus Instruments). Mice were housed individually in air-tight respiratory cages through which room air was passed at a flow rate of $0.5 \mathrm{l} / \mathrm{min}$. Exhaust air was sampled at 27-minute intervals for a period of 1 minute; $\mathrm{O}_{2}$ and $\mathrm{CO}_{2}$ content of the exhaust air was determined by comparison with the $\mathrm{O}_{2}$ and $\mathrm{CO}_{2}$ content of standardized sample air. Mice were acclimatized to the cages for 48 hours before measurements were taken. Lean body mass and fat content were determined using the DEXA method (Dexa Sabre Bone Densitometry; Norland). $\mathrm{VO}_{2}, \mathrm{VCO}_{2}$, and heat production were normalized to lean body mass.

Quantitative real-time PCR analysis. Mice were fasted for 8 hours (from 9:00 am to 5:00 pm) and sacrificed by decapitation. The hypothalamus was isolated immediately, and total hypothalamic RNA was prepared using TRIzOL reagent (Invitrogen). The first-strand cDNAs were synthesized using oligo-dT(12-18) and M-MLV reverse transcriptase (Promega). NPY, POMC, AgRP, and $\beta$-actin mRNA levels were measured using the Brilliant SYBR Green QPCR Kit and Mx3000P Real-Time PCR System (Stratagene). The expression of NPY, AgRP, and POMC was normalized to the expression of $\beta$-actin. Primers for real-time RT-PCR were: NPY sense 5'-TCAGACCTCTTAATGAAGGAAAGCA-3', NPY antisense 5'-GAGAACAAGTTTCATTTCCCATCA-3'; AgRP sense 5'-GGCCTCAAGAAGACAACTGC, AgRP antisense 5'-GACTCGTGCAGCCTTACACA-3'; POMC sense 5'-CTGCTTCAGACCTCCATAGATGTG-3, POMC antisense CAGCGAGAGGTCGAGTTTGC; $\beta$-actin sense 5 '-AAATCGTGCGTGACATCAAA- 3 ', $\beta$-actin antisense 5 '-AAGGAAGGCTGGAAAAGAGC.

Adipocyte differentiation. Confluent 3T3-L1 preadipocytes were grown for 2 additional days in DMEM-high glucose supplemented with $8 \%$ calf serum at $5 \% \mathrm{CO}_{2}$ and $37^{\circ} \mathrm{C}$. Cells were then cultured for 3 days in a differentiation medium (DMEM-high glucose supplemented with 10\% FCS, $0.1 \mu \mathrm{M}$ insulin, $1 \mu \mathrm{M}$ dexamethasone, $0.5 \mathrm{mM}$ 3-isobutyl-1-methylxanthine) and 3 days in DMEM-high glucose supplemented with $10 \%$ FCS, $0.1 \mu \mathrm{M}$ insulin. Differentiated adipocytes were maintained in DMEM-high glucose supplemented with $8 \%$ fetal calf serum. MEF primary cultures were differentiated similarly, except that $0.1 \mu \mathrm{M}$ rosiglitazone was added into the differentiation medium.

Adipocytes were washed with PBS, fixed in 10\% formalin for 5 minutes, stained in oil red $\mathrm{O}$ working solution for 2 hours, and washed extensively with water. Oil red $\mathrm{O}$ working solution was prepared by diluting oil red O stock solution ( $0.5 \%$ in isopropanol) with water to a $6: 4$ ratio. Adipocytes were visualized using a BX51 microscope, and images were captured using a DP70 Digital Camera.

Immunoprecipitation and immunoblotting. Mice were fasted for 24 hours and injected intraperitoneally with leptin ( $1 \mathrm{mg} / \mathrm{kg}$ body weight) or PBS (as control). Forty-five minutes later, mice were sacrificed by decapitation, and the hypothalamus was isolated and homogenized in lysis buffer (50 mM Tris- $\mathrm{HCl}$, pH 7.5, 5 mM EDTA, $10 \mathrm{mM} \mathrm{Na}_{4} \mathrm{P}_{2} \mathrm{O}_{7}, 100 \mathrm{mM}$ $\mathrm{NaF}, 250 \mathrm{mM}$ sucrose, $1 \mathrm{mM} \mathrm{Na} \mathrm{VO}_{4}, 10 \mu \mathrm{g} / \mathrm{ml}$ aprotinin, $10 \mu \mathrm{g} / \mathrm{ml}$ leupeptin, $0.2 \mathrm{mM}$ benzamidine, $2 \mathrm{mM}$ DTT, $1 \%$ Nonidet P-40). The same amount of protein in hypothalamic extracts was immunoblotted with anti-phospho-STAT3 (pTyr705) antibody (Santa Cruz Biotechnology Inc.). The same blots were reprobed with anti-STAT3 antibody (Santa Cruz Biotechnology Inc.) to estimate total STAT3 protein.

Statistics. The data are presented as mean \pm SEM. Two-tailed Student's $t$ tests were used for comparisons between 2 groups. $P<0.05$ was considered statistically significant.

\section{Acknowledgments}

We thank Hongyan Yang and Chaojun Duan for helpful discussions. We thank Streamson Chua Jr. (Albert Einstein College of Medicine) for providing the NSE promoter/GH enhancer. This study was supported by a Career Development Award (7-03-CD-11) from the American Diabetes Association and grants R01 DK 065122 and R01 DK073601 from the NIH (all to L. Rui). D. Morris was supported by a Cellular and Molecular Approaches to Systems and Integrative Biology Training Grant (NIH T32 GM008322). This work utilized the cores supported by the Michigan Diabetes Research and Training Center (funded by NIH grant 5P60 DK20572), University of Michigan Comprehensive Cancer Center (funded by NIH grant 5P30 CA46592), University of Michigan Nathan Shock Center for Excellence in the Basic Biology of Aging, Michigan Gastrointestinal Peptide Research Center, University of Michigan Center for Organogenesis, and University of Michigan Center for Integrative Genomics.

Received for publication June 16, 2006, and accepted in revised form November 21, 2006.

Address correspondence to: Liangyou Rui, Department of Molecular and Integrative Physiology, University of Michigan Medical School, Ann Arbor, Michigan 48109-0622, USA. Phone: (734) 615-7544; Fax: (734) 647-9523; E-mail: ruily@umich.edu.

Decheng Ren and Yingjiang Zhou contributed equally to this work.
1. Flier, J.S. 2004. Obesity wars: molecular progress confronts an expanding epidemic. Cell. 116:337-350.

2. Friedman, J.M., and Halaas, J.L. 1998. Leptin and the regulation of body weight in mammals. Nature. 395:763-770.

3. Schwartz, M.W., and Porte, D., Jr. 2005. Diabetes, obesity, and the brain. Science. 307:375-379.

4. Zhang, Y., et al. 1994. Positional cloning of the mouse obese gene and its human homologue. Nature. 372:425-432.

5. Chua, S.C., Jr., et al. 1996. Phenotypes of mouse diabetes and rat fatty due to mutations in the $\mathrm{OB}$ (leptin) receptor. Science. 271:994-996.

6. Chen, H., et al. 1996. Evidence that the diabetes gene encodes the leptin receptor: identification of a mutation in the leptin receptor gene in $\mathrm{db} / \mathrm{db}$ mice. Cell. 84:491-495.

7. Lee, G.H., et al. 1996. Abnormal splicing of the leptin 
receptor in diabetic mice. Nature. 379:632-635.

8. Vaisse, C., et al. 1996. Leptin activation of Stat3 in the hypothalamus of wild-type and ob/ob mice but not db/db mice. Nat. Genet. 14:95-97.

9. Bjorbaek, C., Uotani, S., da Silva, B., and Flier, J.S. 1997. Divergent signaling capacities of the long and short isoforms of the leptin receptor. J. Biol. Chem. 272:32686-32695.

10. Baumann, H., et al. 1996. The full-length leptin receptor has signaling capabilities of interleukin 6-type cytokine receptors. Proc. Natl. Acad. Sci.U.S. A. 93:8374-8378

11. Zhao, A.Z., Huan, J.N., Gupta, S., Pal, R., and Sahu, A. 2002. A phosphatidylinositol 3-kinase phosphodiesterase 3B-cyclic AMP pathway in hypothalamic action of leptin on feeding. Nat. Neurosci. 5:727-728.

12. Niswender, K.D., et al. 2001. Intracellular signalling. Key enzyme in leptin-induced anorexia. Nature. 413:794-795.

13. Bates, S.H., et al. 2003. STAT3 signalling is required for leptin regulation of energy balance but not reproduction. Nature. 421:856-859.

14. Cui, Y., et al. 2004. Essential role of STAT3 in body weight and glucose homeostasis. Mol. Cell. Biol. 24:258-269.

15. Gao, Q., et al. 2004. Disruption of neural signal transducer and activator of transcription 3 causes obesity, diabetes, infertility, and thermal dysregulation. Proc. Natl. Acad. Sci. U. S. A. 101:4661-4666.

16. Suzuki, R., et al. 2004. Both insulin signaling defects in the liver and obesity contribute to insulin resistance and cause diabetes in Irs2(-/-) mice. J. Biol. Chem. 279:25039-25049.

17. Lin, X., et al. 2004. Dysregulation of insulin receptor substrate 2 in $\beta$ cells and brain causes obesity and diabetes. J. Clin. Invest. 114:908-916. doi:10.1172/JCI200422217.

18. Banks, A.S., Davis, S.M., Bates, S.H., and Myers, M.G., Jr. 2000. Activation of downstream signals by the long form of the leptin receptor. J. Biol. Chem. 275:14563-14572.

19. Bjorbaek, C., and Kahn, B.B. 2004. Leptin signaling in the central nervous system and the periphery. Recent Prog. Horm. Res. 59:305-331.

20. Myers, M.P., et al. 2001. TYK2 and JAK2 are substrates of protein-tyrosine phosphatase 1B. J. Biol. Chem. 276:47771-47774.

21. Cheng, A., et al. 2002. Attenuation of leptin action and regulation of obesity by protein tyrosine phosphatase 1B. Dev. Cell. 2:497-503.

22. Zabolotny, J.M., et al. 2002. PTP1B regulates leptin signal transduction in vivo. Dev. Cell. 2:489-495

23. Bjorbaek, C., Elmquist, J.K., Frantz, J.D., Shoelson, S.E., and Flier, J.S. 1998. Identification of SOCS-3 as a potential mediator of central leptin resistance. Mol. Cell. 1:619-625.

24. Ungureanu, D., Saharinen, P., Junttila, I., Hilton, D.J., and Silvennoinen, O. 2002. Regulation of Jak2 through the ubiquitin-proteasome pathway involves phosphorylation of Jak2 on Y1007 and interaction with SOCS-1. Mol. Cell. Biol. 22:3316-3326.

25. Howard, J.K., et al. 2004. Enhanced leptin sensitivity and attenuation of diet-induced obesity in mice with haploinsufficiency of Socs3. Nat. Med. 10:734-738.

26. Mori, H., et al. 2004. Socs3 deficiency in the brain elevates leptin sensitivity and confers resistance to diet-induced obesity. Nat. Med. 10:739-743.

27. Rui, L., and Carter-Su, C. 1999. Identification of $\mathrm{SH} 2$-bbeta as a potent cytoplasmic activator of the tyrosine kinase Janus kinase 2. Proc. Natl. Acad. Sci. U. S. A. 96:7172-7177.

28. Osborne, M.A., Dalton, S., and Kochan, J.P. 1995 The yeast tribrid system - genetic detection of trans-phosphorylated ITAM-SH2-interactions. Biotechnology (N. Y.). 13:1474-1478.

29. Rui, L., Mathews, L.S., Hotta, K., Gustafson, T.A., and Carter-Su, C. 1997. Identification of SH2 Bbeta as a substrate of the tyrosine kinase JAK2 involved in growth hormone signaling. Mol. Cell. Biol. 17:6633-6644.

30. Yokouchi, M., et al. 1997. Cloning and characterization of APS, an adaptor molecule containing $\mathrm{PH}$ and $\mathrm{SH} 2$ domains that is tyrosine phosphorylated upon B-cell receptor stimulation. Oncogene. 15:7-15.

31. Yousaf, N., Deng, Y., Kang, Y., and Riedel, H. 2001. Four PSM/SH2-B alternative splice variants and their differential roles in mitogenesis. J. Biol. Chem. 276:40940-40948.

32. Kotani, K., Wilden, P., and Pillay, T.S. 1998. SH2Balpha is an insulin-receptor adapter protein and substrate that interacts with the activation loop of the insulin-receptor kinase. Biochem. J. 335:103-109.

33. Nelms, K., et al. 1999. Alternative splicing, gene localization, and binding of SH2-B to the insulin receptor kinase domain. Mamm. Genome. 10:1160-1167.

34. Qian, X., Riccio, A., Zhang, Y., and Ginty, D.D. 1998. Identification and characterization of novel substrates of Trk receptors in developing neurons. Neuron. 21:1017-1029.

35. Riedel, H., Wang, J., Hansen, H., and Yousaf, N. 1997. PSM, an insulin-dependent, pro-rich, $\mathrm{PH}$ $\mathrm{SH} 2$ domain containing partner of the insulin receptor. J. Biochem. (Tokyo). 122:1105-1113.

36. Rui, L., and Carter-Su, C. 1998. Platelet-derived growth factor (PDGF) stimulates the association of SH2-Bbeta with PDGF receptor and phosphorylation of SH2-Bbeta. J. Biol. Chem. 273:21239-21245.

37. Rui, L., Herrington, J., and Carter-Su, C. 1999. SH2-B, a membrane-associated adapter, is phosphorylated on multiple serines/threonines in response to nerve growth factor by kinases within the MEK/ERK cascade. J. Biol. Chem. 274:26485-26492.

38. Rui, L., Herrington, J., and Carter-Su, C. 1999. SH2-B is required for nerve growth factor-induced neuronal differentiation. J. Biol. Chem. 274:10590-10594.

39. Suzuki, K., et al. 2002. Association of SH2-B to phosphorylated tyrosine residues in the activation loop of TrkB. Res. Commun. Mol. Pathol. Pharmacol. 111:27-39.

40. Wang, J., and Riedel, H. 1998. Insulin-like growth factor-I receptor and insulin receptor association with a Src homology-2 domain-containing putative adapter. J. Biol. Chem. 273:3136-3139.

41. Zhang, Y., et al. 2006. Interaction of SH2-Bbeta with RET is involved in signaling of GDNF-induced neurite outgrowth. J. Cell Sci. 119:1666-1676.

42. Kong, M., Wang, C.S., and Donoghue, D.J. 2002. Interaction of fibroblast growth factor receptor 3 and the adapter protein SH2-B. A role in STAT5 activation. J. Biol. Chem. 277:15962-15970.

43. O'Brien, K.B., O'Shea, J.J., and Carter-Su, C. 2002. SH2-B family members differentially regulate JAK family tyrosine kinases. J. Biol. Chem. 277:8673-8681.

44. Duan, C., Yang, H., White, M.F., and Rui, L. 2004. Disruption of the SH2-B gene causes age-dependent insulin resistance and glucose intolerance. Mol. Cell. Biol. 24:7435-7443.

45. Ren, D., Li, M., Duan, C., and Rui, L. 2005. Identification of SH2-B as a key regulator of leptin sensitivity, energy balance, and body weight in mice. Cell Metab. 2:95-104

46. Li, M., Ren, D., Iseki, M., Takaki, S., and Rui, L. 2006. Differential role of SH2-B and APS in regulating energy and glucose homeostasis. Endocrinology. 147:2163-2170.

47. Ohtsuka, S., et al. 2002. SH2-B is required for both male and female reproduction. Mol. Cell. Biol. 22:3066-3077.

48. Kowalski, T.J., Liu, S.-M., Leibel, R.L., and Chua, S.C., Jr. 2001. Transgenic complementation of leptin-receptor deficiency. I. Rescue of the obesity/ diabetes phenotype of LEPR-null mice expressing a LEPR-B transgene. Diabetes. 50:425-435.

49. Mizuno, T.M., Kelley, K.A., Pasinetti, G.M., Roberts, J.L., and Mobbs, C.V. 2003. Transgenic neuronal expression of proopiomelanocortin attenuates hyperphagic response to fasting and reverses metabolic impairments in leptin-deficient obese mice. Diabetes. 52:2675-2683.

50. Cone, R.D. 2005. Anatomy and regulation of the central melanocortin system. Nat. Neurosci. 8:571-578.

51. Seeley, R.J., Drazen, D.L., and Clegg, D.J. 2004. The critical role of the melanocortin system in the control of energy balance. Annu. Rev. Nutr. 24:133-149.

52. Ahmed, Z., and Pillay, T.S. 2003. Adapter protein with a pleckstrin homology $(\mathrm{PH})$ and an Src homology 2 (SH2) domain (APS) and SH2-B enhance insulin-receptor autophosphorylation, extracellular-signal-regulated kinase and phosphoinositide 3-kinase-dependent signalling. Biochem. J. 371:405-412.

53. Bruning, J.C., et al. 2000. Role of brain insulin receptor in control of body weight and reproduction. Science. 289:2122-2125.

54. Benoit, S.C., Clegg, D.J., Seeley, R.J., and Woods, S.C. 2004. Insulin and leptin as adiposity signals. Recent Prog. Horm. Res. 59:267-285.

55. Hu, J., and Hubbard, S.R. 2006. Structural basis for phosphotyrosine recognition by the Src homology-2 domains of the adapter proteins SH2-B and APS. J. Mol. Biol. 361:69-79.

56. Kurzer, J.H., et al. 2004. Tyrosine 813 is a site of JAK2 autophosphorylation critical for activation of JAK2 by SH2-B beta. Mol. Cell. Biol. 24:4557-4570.

57. Nishi, M., et al. 2005. Kinase activation through dimerization by human SH2-B. Mol. Cell. Biol. 25:2607-2621.

58. Duan, C., Li, M., and Rui, L. 2004. SH2-B promotes insulin receptor substrate 1 (IRS1)- and IRS2mediated activation of the phosphatidylinositol 3-kinase pathway in response to leptin. J. Biol. Chem. 279:43684-43691.

59. White, M.F. 2002. IRS proteins and the common path to diabetes. Am. J. Physiol. Endocrinol. Metab. 283:E413-E422.

60. Balthasar, N., et al. 2005. Divergence of melanocortin pathways in the control of food intake and energy expenditure. Cell. 123:493-505.

61. Pocai, A., et al. 2005. Central leptin acutely reverses diet-induced hepatic insulin resistance. Diabetes. 54:3182-3189.

62. Morton, G.J., et al. 2005. Leptin regulates insulin sensitivity via phosphatidylinositol-3-OH kinase signaling in mediobasal hypothalamic neurons. Cell Metab. 2:411-420.

63. Inoue, H., et al. 2006. Role of hepatic STAT3 in brain-insulin action on hepatic glucose production. Cell Metab. 3:267-275.

64. Gelling, R.W., et al. 2006. Insulin action in the brain contributes to glucose lowering during insulin treatment of diabetes. Cell Metab. 3:67-73.

65. Obici, S., Feng, Z., Karkanias, G., Baskin, D.G., and Rossetti, L. 2002. Decreasing hypothalamic insulin receptors causes hyperphagia and insulin resistance in rats. Nat. Neurosci. 5:566-572.

66. Obici, S., Zhang, B.B., Karkanias, G., and Rossetti, L. 2002. Hypothalamic insulin signaling is required for inhibition of glucose production. Nat. Med. 8:1376-1382. 